\title{
Jornalismo e gênero: a emergência de uma disciplina e um relato de docência compartilhada
}

\author{
Daiane Bertasso' (1D) 0000-0002-7528-3709 \\ Fernanda Nascimento' (D) 0000-0003-2332-5396 \\ Jessica Gustafson' (iD) 0000-0002-7056-9046 \\ 'Universidade Federal de Santa Catarina, Florianópolis, SC, Brasil. \\ 88040-900 - jornalismo@contato.ufsc.br
}

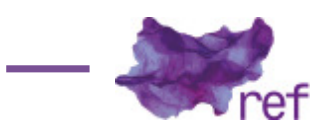

Resumo: Neste artigo apresentamos o surgimento da disciplina Jornalismo e Gênero no curso de Jornalismo da Universidade Federal de Santa Catarina (UFSC) e debate sobre a sua necessidade e emergência na formação de jornalistas. Os debates no campo do Jornalismo sobre/a partir das temáticas de Gênero ainda são incipientes, apesar da urgência da construção de discussões que repensem as práticas da profissão, as relações entre os profissionais e o ensino. Neste relato, tecemos algumas considerações sobre nossa experiência docente à frente da disciplina, apresentando os avanços, dificuldades e procurando contribuir para o crescimento do campo e a construção de conhecimento sobre os temas de Gênero no Jornalismo.

Palavras-chave: Jornalismo; gênero; educação; docência; ensino superior.

Journalism And Gender: A Rising of a Subject and a Shared Teaching Report

Abstract: This article presents the rising if the subjetive known as Journalism and Gender in Journalism Course of Universidade Federal de Santa Catarina (UFSC) and discusses its needs and emergence on journalists' education. The discussions in Journalism area about/from Gender topics are still incipient, in spite of construction of discussions that reconsider journalism practices urgency, relationships between professionals and teaching. In this report, some observations were made about our experience teaching this subject, showing advances, struggles and seeking to contribute to the growth of the area and the construction of knowledge about Gender topics in Journalism.

Keywords: Journalism; Gender; Education; Teaching; College education.

\section{Introdução}

Transgredir, no sentido de desacomodar, instigar, desconstruir determinadas maneiras tradicionais de pensar as relações de gênero historicamente constituídas socialmente. Este foi o principal objetivo da disciplina Jornalismo e Gênero da Universidade Federal de Santa Catarina (UFSC) e o mote inicial daquele seis de março de 2017, o primeiro encontro com a turma, um dia inesquecível para nós docentes e, certamente, para os estudantes de Jornalismo da UFSC que participaram da disciplina e da dinâmica de abertura intitulada Caminhada dos Privilégios. Iniciamos a caminhada em espaço aberto, fora da sala de aula, lado a lado, e fomos respondendo às perguntas realizadas por uma das docentes, também participante da caminhada. Conforme a pergunta cada pessoa deveria dar um passo à frente ou um passo para trás. Foram 30 perguntas, tais como: 1. Se os seus pais trabalharam noites e finais de semana para sustentar a sua família, dê um passo para trás. (Classe); 2. Se você consegue andar pelo mundo sem sentir medo de assédio sexual, dê um passo para frente. (Gênero); 3. Se você consegue demonstrar afeto pelo seu 
companheiro romântico em público sem sentir medo de ridicularização ou violência, dê um passo para frente. (Gênero e Sexualidade); 4. Se você já foi diagnosticado com alguma doença ou deficiência mental/física, dê um passo para trás. (Capacitismo); 5 . Se você veio de um ambiente familiar que te apoiava, dê um passo para frente. (Classe, Gênero, Sexualidade). Ao final dos 30 questionamentos já não estávamos lado a lado na Caminhada dos Privilégios, já que os mais privilegiados estavam à frente, enquanto que os menos ou muito pouco privilegiados estavam mais atrás, alguns até no final do caminho, e todos se visualizaram e sentiram o impacto das diferenças - mesmo estando em grupo formado por inúmeras semelhanças, como estarem no ensino superior e possuírem entre 18 e 26 anos.

Ao retornarmos ao debate em sala de aula, a participação da turma foi ampla e gratificante. Pudemos refletir sobre privilégios, identidades, diferenças, desigualdades, preconceitos de classe, raça, gênero, religião etc. Essa foi a aula inaugural da disciplina Jornalismo e Gênero, que reuniu cerca de 30 estudantes e teve mais 16 encontros no decorrer do primeiro semestre de 2017 , em que debatemos sobre identidades, diferenças, desigualdades, gênero, práticas culturais e discursivas, relações de poder, movimentos feministas, sexualidade etc. até chegarmos na abordagem sobre os avanços conquistados por meio de resistências e transgressões na perspectiva de gêneros em Comunicação e Jornalismo. Será um pouco dessa experiência que vamos relatar neste artigo.

O campo dos Estudos de Gênero se consolidou a partir da segunda metade do século XX (Joana Maria PEDRO, 2005). Em sua emergência, este debate estava associado a uma discussão sobre problemáticas relacionadas às mulheres (PEDRO, 2005). Posteriormente, ainda que não sem disputas e tensionamentos (Donna HARAWAY, 2004), o conceito se desloca da compreensão de uma relação binária e oposta entre homens e mulheres, para um campo de disputas de poder.

Neste sentido, nos associamos à Joan Scott (1995), compreendendo o gênero como "elemento constitutivo das relações sociais baseado nas diferenças percebidas entre os sexos", ou seja, "uma forma primeira de significar as relações de poder" (SCOT, 1995, p. 21). Como afirma Teresa de Lauretis (1994, p. 208): o gênero não é "uma propriedade de corpos nem algo existente a priori nos seres humanos".

Categoria fundamental para a constituição e organização das sociedades colonizadoras e colonizadas no Ocidente, o sistema sexo/gênero é uma das formas primordiais de regulação dos corpos e das instituições (María LUGONES, 2014). Nestas sociedades generificadas, como no Brasil, esta construção acontece a partir dos mais diversos espaços, sendo o Jornalismo um dos locais privilegiados no processo. Esfera de mediação e também de construção de sentidos, o Jornalismo é um dos espaços sociais de consolidação e/ou transformação dos valores sociais.

Se o "Jornalismo é masculino", tal qual nos demonstrou Marcia Veiga da Silva (2014), a construção deste posicionamento ocorre em articulação com a sociedade na qual se insere, mas também na agência dos sujeitos que constituem o campo. E neste processo, a universidade é um espaço privilegiado nesta formação e tem, com raras exceções, reproduzido valores sociais dominantes masculinistas, racistas e cisheteronormativos. Conforme Veiga da Silva (2015), ao analisar especificamente o contexto do ensino de Jornalismo, persiste uma "prevalência das racionalidades do sistema-mundo (capitalista, masculinista, racista, heterossexista, ocidentalista) nas relações de poder e de saber no âmbito universitário" (p. 262).

Estas visões de mundo, compartilhadas em todas as esferas, começaram a ser problematizadas há algumas décadas por outras áreas do conhecimento. Entretanto, a produção reflexiva na comunicação, realizada por pesquisadores do próprio campo, ainda é recente e escassa (Ana Carolina D. ESCOSTEGUY; Márcia MESSA, 2006; Monica MARTINEZ; Cláudia LAGO; Mara Coelho de Souza LAGO, 2016; Tainan Pauli TOMAZETI; Paula CORUJA, 2017; Gabriela ALMEIDA, 2018; VEIGA DA SILVA, 2014; 2015; Jessica GUSTAFSON, 2019). Destaca-se que esta é uma área em emergência e este panorama pode se alterar, com o tensionamento oriundo de alunos, que começam a demandar, a partir de coletivos ou por meio de suas pesquisas, um ensino de Jornalismo que contemple as discussões de gênero e as problemáticas que necessariamente devem acompanhá-las, como de raça, sexualidade e classe.

Com a proposta de contribuir para o debate, refletimos neste texto sobre a nossa experiência coletiva docente de lecionar a disciplina de Jornalismo e Gênero, no Departamento de Jornalismo da Universidade Federal de Santa Catarina (UFSC), no primeiro semestre de 2017.

\section{A criação da disciplina e o Coletivo Jornalismo Sem Machismo}

A criação da disciplina de Jornalismo e Gênero no Departamento de Jornalismo da UFSC está diretamente relacionada à emergência do Coletivo Jornalismo Sem Machismo. A organização estudantil surgiu no segundo semestre de 2014, a partir das demandas de alunas do curso de Jornalismo da UFSC. De acordo com a página oficial do grupo, a criação do Coletivo Jornalismo Sem Machismo aconteceu após "uma roda de conversa sobre o machismo presente no curso e na profissão", na qual as alunas dividiram histórias e problemas em comum (COLETIVO JORNALISMO SEM MACHISMO, 2018). 
Entre as reivindicações do Coletivo junto à coordenação do Departamento de Jornalismo da UFSC, estava a criação da disciplina de Jornalismo e Gênero, compreendida como um espaço fundamental para as discussões sobre a responsabilidade do Jornalismo na produção/reprodução de narrativas que perpetuam o machismo, o sexismo e a misoginia - além de sua importância para a mudança nas próprias relações entre os integrantes da comunidade acadêmica.

O tensionamento culminou na realização da primeira edição da disciplina, no primeiro semestre de 2016. A coletividade foi uma das marcas deste primeiro momento: o professor Carlos Augusto Locatelli, então chefe do Departamento, foi responsável pela disciplina e construiu o plano de ensino de modo conjunto com as integrantes do Coletivo. Neste primeiro momento, o plano de ensino foi composto por aulas lecionadas por professoras convidadas, oriundas de diversas áreas de ensino, mas com pesquisas consolidadas no campo de estudos de gênero. A demanda dos alunos pela disciplina pode ser observada na quantidade de inscrições, que superou o número de vagas - assim como ocorreria também na segunda edição da disciplina (no primeiro semestre de 2017), que apresentaremos na sequência.

Na finalização da primeira edição da disciplina, os(as) alunos(as) participantes responderam a um questionário dotado das seguintes perguntas: "O que achou do formato de uma professora por aula? Como avalia a falta de textos para leitura? Os temas eram relevantes ou repetitivos? Sentiu falta de algum assunto? O nível das aulas estava correto, muito aprofundado ou iniciante? O que achou do trabalho final? Críticas e sugestões". A maioria dos respondentes avaliou positivamente o formato e os temas, mas sentiu falta de uma estruturação da ordem dos conteúdos e de leituras básicas. Essa pesquisa foi utilizada por nós nas reuniões de planejamento para a edição de $2017 / 1$ da disciplina. Um pouco da percepção das alunas do Coletivo Jornalismo Sem Machismo pode ser conferida no relato de experiência apresentado no I Aquenda de Comunicação, Gêneros e Sexualidades:

\begin{abstract}
Organizamos o plano de ensino de forma que, para cada tema específico, fosse possível trazer uma pesquisadora do assunto como convidada, já que não havia essa formação acadêmica suficiente seja por parte docente ou discente no Departamento de Jornalismo da UFSC. Porém, ainda que a presença das convidadas tenha acrescentado muito à disciplina, a metodologia das aulas variava bastante, pois dependia da palestrante e as aulas tinham alguma dificuldade de dialogar entre si. Também era bastante novo para nós sermos responsáveis pelas questões metodológicas e de ensino, pois, por mais que houvesse nosso esforço - e ainda que tenha sido uma experiência bastante enriquecedora -, não éramos professoras (Eduarda PEREIRA; Manoela dos Santos BONALDO, 2018 [online]).
\end{abstract}

Em agosto de 2016, houve um impasse sobre a realização da segunda edição e foi neste momento em que nos reunimos para construir esta edição da disciplina. Neste encontro de mulheres feministas e pesquisadoras do campo da Comunicação Social, se fizeram presentes diferentes experiências e contribuições: Daiane Bertasso, Professora Adjunta do Departamento de Jornalismo da UFSC, iniciava seus estudos no campo de gênero; Fernanda Nascimento e Jessica Gustafson, doutoranda e mestranda (na época), respectivamente, já tinham trajetória de pesquisa e militância, sendo a disciplina o espaço escolhido para os estágios de docência.

Em nossos primeiros encontros, com a parceria voluntária da Professora Substituta na época, Silvia Mendes, definimos a importância de dialogar com as alunas integrantes do Coletivo Jornalismo Sem Machismo. Fizemos o convite para que pudessem discutir conosco teorias e metodologias, a partir da primeira experiência da disciplina. Ao longo dos encontros, dialogamos com Aline Ramalho e Manoela dos Santos Bonaldo, que participaram como representantes do Coletivo Jornalismo Sem Machismo. Foi na troca entre alunas, professoras e estagiárias docentes que elaboramos os conteúdos que são apresentados a seguir, conforme corrobora o relato das representantes do coletivo:

Durante sucessivas reuniões junto com as representantes do Coletivo e as estagiárias de docência, foi criado o plano de ensino que é usado atualmente. Finalmente, no início de 2017 a disciplina foi implementada no currículo oficial do curso. Hoje ela é oferecida como uma optativa e possui grande demanda. A construção desse novo plano, agora com a participação de mulheres que já pesquisavam gênero e comunicação, somadas à experiência adquirida pelas alunas e ao conhecimento didático da professora Daiane, possibilitou que a disciplina se consolidasse na grade do curso. As transformações no curso, que envolvem o surgimento do Coletivo e a criação da disciplina de Jornalismo e Gênero, apontam para a importância da relação entre os movimentos sociais e a produção de conhecimento acadêmico (PEREIRA; BONALDO, 2018 [online]).

\title{
Saberes em produção: a organização dos conteúdos
}

A primeira edição da disciplina, como apresentado anteriormente, foi marcada pela fragmentação do conteúdo, em decorrência de seu formato, abordado de acordo com a contribuição de diversas professoras convidadas. A partir da avaliação desta primeira edição, compreendemos a necessidade de trabalhar por meio de um referencial mais consistentemente 
organizado e, em alguma medida, linear, situando o Jornalismo em uma perspectiva comunicacional, enquanto uma prática social e cultural, que contribui na manutenção das desigualdades de gênero, raça, sexualidade, geração e etnia, a partir do debate de cada conceito.

Organizamos a disciplina em três módulos, sendo o primeiro sobre as temáticas de Gênero, cultura, linguagem e poder (1), com aulas específicas para trabalhar as seguintes questões: Identidade, diferença e desigualdades; - Teorias de gênero; - Práticas culturais e discursivas que evidenciam relações de gênero e relações de poder. No segundo módulo, tratamos sobre Gênero e interseccionalidades (2), com o intuito de refletir sobre: - Movimentos Feministas; - Gênero e sexualidade; - Gênero, raça, classe, etnia e geração; - Masculinidades e identidades trans. $O$ terceiro módulo da disciplina foi Representações de gênero, mídia e jornalismo (3), em que trabalhamos as seguintes questões: - Representações de gênero nas mídias; - Questões de gênero abordadas pelo Jornalismo; - Resistências e transgressões na perspectiva de gêneros em Comunicação e Jornalismo. Os principais aspectos trabalhados em cada módulo serão descritos a seguir.

Desta forma, iniciamos a disciplina com uma abordagem mais geral sobre identidades e as relações de poder existentes na linguagem e na produção discursiva, conduzindo os alunos na reflexão sobre o Jornalismo enquanto uma esfera de produção simbólica, atuante também na construção das identidades. Para tratar deste eixo, tivemos como enfoque o processo de classificação existente na construção da linguagem, que transforma a diferença em desigualdade social a partir da hierarquização, como destaca Tomaz Tadeu da Silva (2000):

São outras tantas marcas da presença poder: incluir/excluir ("estes pertencem, aqueles não"); demarcar fronteiras ("nós e eles"); classificar ("bons e maus"; "puros e impuros"; "desenvolvidos e primitivos"; "racionais e irracionais"); normalizar ("nós somos normais, eles são anormais") ( p. 81).

Ao discutir sobre os essencialismos e estereótipos presentes nos discursos jornalísticos, partimos da perspectiva de Stuart Hall (2005) sobre a fragmentação das identidades, em que a concepção moderna de existência de um sujeito centrado e com uma identidade fixa passa por uma série de rupturas teóricas, incluindo a atuação feminista. As identidades são vistas, assim, como fragmentadas, múltiplas, inacabadas e até mesmo contraditórias.

Posteriormente, iniciamos a abordagem sobre as Teorias de Gênero, dividindo o conteúdo em duas aulas. Frente à diversidade de perspectivas construídas em décadas de militância feminista dentro e fora da academia, nossa opção foi intercalar textos clássicos sobre gênero, mas que demonstram as diferentes frentes de pensamento, incluindo o feminismo descolonial, com autoras que realizam análises sobre a importância desses estudos no contexto brasileiro. Entre as autoras deste primeiro momento estavam teóricas brasileiras como Guacira Lopes Louro (2008) e Joana Maria Pedro (2005) e internacionais, como Donna Haraway (1995; 2004), Joan Scott (1995) e María Lugones (2014).

A proposta deste primeiro eixo era demonstrar que os Estudos de Gênero, enquanto disciplina teórica, se sustentam em um amplo e sólido lastro teórico, conhecido hegemonicamente como tendo seu início na Europa e nos Estados Unidos, mas que está em contínuo tensionamento. A leitura do texto de Lugones (2014) certamente foi a que exigiu maior esforço, pois a teórica faz uma ruptura com categorias da Modernidade muito consolidadas dentro do próprio feminismo, ao abordar a racialização dos corpos como processo interligado à colonização do gênero. Entendemos que a compreensão total do texto demanda uma carga de leitura prévia tanto dos Estudos de Gênero quanto dos Estudos Descoloniais. Contudo, o objetivo foi demonstrar a potência e existência de estudos críticos elaborados na América Latina que levam em consideração as experiências das mulheres não brancas no violento processo de colonização moderno:

A consequência semântica da colonialidade do gênero é que "mulher colonizada" é uma categoria vazia: nenhuma mulher é colonizada; nenhuma fêmea colonizada é mulher. Assim, a resposta colonial a Sojourner Truth é, obviamente, "não". Diferentemente da colonização, a colonialidade do gênero ainda está conosco; é o que permanece na intersecção de gênero/ classe/raça como construtos centrais do sistema de poder capitalista mundial. Pensar sobre a colonialidade do gênero permite-nos pensar em seres históricos compreendidos como oprimidos apenas de forma unilateral (LUGONES, 2014, p. 939).

O interesse em conhecer as teorias de gênero pelos alunos e a consequente importância destas primeiras aulas puderam ser percebidas ainda no início da disciplina. Em nosso primeiro encontro, vários alunos expuseram que seu interesse na disciplina estava na ampliação de sua capacidade teórica, que poderia balizar experiências de militância que já mantinham dentro e fora da universidade. Desta forma, consideramos importante realizar uma aula apresentando as correntes feministas contemporâneas. Inicialmente propomos às integrantes do Coletivo Jornalismo Sem Machismo para que elas conduzissem a apresentação, realizando uma pesquisa prévia sobre o tema. Entretanto, tivemos dificuldade em contatá-las e organizar definitivamente a proposta. 
Decidimos, por fim, dividir entre nós as vertentes que consideramos as mais mobilizadoras atualmente para apresentação (Feminismo Negro; Feminismo Interseccional/Pós-Moderno; Feminismo Materialista/Radical; Feminismo Liberal; Feminismo Socialista; Transfeminismo; Anarcofeminismo/ Feminismo Libertário; Ecofeminismo; Feminismo Descolonial). Juntamente com as pesquisas realizadas em sites, blogs e textos acadêmicos sobre as correntes feministas, propomos a leitura, para a turma, de mais dois textos escritos por Betty Friedan (1971) e Cynthia Andersen Sarti (2004).

Com a primeira leitura (FRIEDAN, 1971), o intuito foi ilustrar a discussão teórica relacionada ao emblemático período da chamada "segunda onda" do feminismo, permeada pelo sentimento de descontentamento das mulheres brancas, heterossexuais e de classe média norte-americanas e que, posteriormente, foi muito contestada pelas mulheres negras, latinas e lésbicas que não se viam incluídas nas pautas de luta do movimento. A segunda leitura (SARTI, 2004) faz um apanhado do movimento feminista brasileiro a partir desta época, trazendo as especificidades locais da militância, principalmente no que se refere ao contexto de ditadura militar enfrentado pelas feministas.

Uma situação interessante, que demonstra a necessidade de permanência do diálogo com os alunos e de escuta de suas demandas, ocorreu no encerramento do segundo mês de aula. Percebendo que a maioria dos alunos não conseguia ler todos os textos definidos para as aulas, conversamos com toda a turma para saber a avaliação que estavam fazendo sobre o andamento da disciplina. A maioria dos alunos afirmou que tentava realizar a leitura dos textos (geralmente dois por aula), mas que acabava conseguindo, de fato, ler apenas um deles (geralmente aquele com menor número de páginas). A carga horária de outras disciplinas e a realização de estágios fora da universidade foram apresentados como dificuldades. Nesse momento, repensamos a proposta, limitando a um texto obrigatório por aula e dialogamos sobre a responsabilidade compartilhada do aprendizado, o que tornou as discussões mais interessantes e engajadas.

Após a abordagem mais geral dos Estudos de Gênero, iniciamos o eixo sobre as interseccionalidades de gênero, sexualidade, raça, etnia, classe e geração, perspectiva que consideramos de extrema importância para refletir sobre a construção das notícias jornalísticas a partir do entendimento de que gênero não opera sozinho e que outros marcadores de diferença situam os sujeitos em diferentes posições de opressão e privilégio.

Formulado por Kimberlé Crenshaw (2004), o conceito de discriminação interseccional parte do reconhecimento dos direitos das mulheres enquanto direitos humanos, no âmbito internacional, do mesmo modo como a discriminação racial é condenada como uma violação de direitos humanos. Entretanto, a questão do racismo articulado ao gênero não era tratada de uma forma específica, sendo necessário que se compreendesse que "homens e mulheres podem experimentar situações de racismo de maneiras especificamente relacionadas ao seu gênero" (CRENSHAW, 2004, p. 9). As articulações mais específicas entre gênero, raça e classe foram debatidas a partir de Angela Davis (2016), que enfatiza a indissolubilidade das lutas no contexto da militância feminista:

Como a abolição da escravatura era a necessidade política mais premente da época, elas incitavam as mulheres a se juntar à luta a partir da premissa de que a sua própria opressão era sustentada e perpetuada pela continuidade do sistema escravagista. Por terem uma consciência tão profunda na indissociabilidade entre a luta pela libertação negra e pela libertação feminina, as irmãs nunca caíram na armadilha ideológica de insistir que um combate era mais importante do que o outro. Elas reconheciam o caráter dialético da relação entre as duas causas (p. 56).

Na continuação do módulo sobre interseccionalidades, discutimos sobre gênero e sexualidade, um dos temas mais aguardados pelos alunos. A proposta de textos para essa aula precisou ser, inclusive, atualizada em decorrência da demanda da turma. Inicialmente pensamos em trabalhar a partir de textos clássicos sobre sexualidade (Gayle RUBIN, 2017) e, de forma mais específica, sobre homossexualidade (Peter FRY; Edward MacRAE, 1991), mas com uma demanda de discussão mais específica sobre bissexualidade apresentada pela turma, utilizamos também textos deste campo (Fernando SEFFNER, 2004).

O eixo de interseccionalidades contou ainda com a discussão sobre masculinidades, tendo como enfoque os discursos midiáticos que reforçam a masculinidade hegemônica (Luiz Paulo da MOITA LOPES, 2006) e as identidades trans enquanto expressão identitária que revela divergências com as normas de gênero, que são fundadas no dimorfismo sexual, na heterossexualidade e em idealizações (Berenice BENTO, 2008). Por fim, o encerramento deste segundo eixo contou com as contribuições dos estudos Queer (Judith BUTLER, 2013), com a presença do doutorando em Comunicação Social da UFRGS, Dieison Marconi.

No eixo de encerramento teórico da disciplina, apresentamos discussões mais específicas sobre a mídia e gênero, discutindo pesquisas que versaram sobre o tema (VEIGA DA SILVA, 2014; Fernanda NASCIMENTO, 2015; Pâmela STOCKER; Silvana DALMASO, 2016; Rosa Maria Bueno FISCHER, 2002). Após todas as discussões realizadas em aula, acreditamos ter ficado mais compreensível aos alunos o entendimento de que gênero extrapola os corpos, constituindo e sendo constituído 
pelas instituições sociais e práticas sociais. De acordo com Veiga da Silva (2014), a generificação no Jornalismo, enquanto uma dessas instituições, acontece a partir da reprodução das relações de gênero e de poder hegemonicamente prevalecentes na cultura, tanto nas relações dentro das redações quanto nas notícias produzidas, refletindo em hierarquias e desigualdades.

Por fim, concluímos o conteúdo da disciplina demonstrando que existem resistências dentro do campo, que têm se empenhado na construção de sentidos alternativos que se opõem aos discursos masculinistas, racistas e cisheteronormativos presentes na mídia. Entre os exemplos de experiências transgressoras no Jornalismo, convidamos Paula Guimarães, uma das jornalistas do portal Catarinas, criado em 2016, na cidade Florianópolis-SC, a partir de uma campanha de financiamento coletivo, para conversar com a turma sobre a experiência de criação do portal.

\section{Metodologias: processos de ensino e aprendizagem}

O desafio de lecionar uma disciplina de Jornalismo e Gênero se estende para a metodologia de ensino utilizada. Refletir sobre gênero significa também refletir sobre o processo de ensino e aprendizagem. Neste sentido, apresentamos como proposta a realização de aulas expositivas e dialogadas, nas quais a participação dos alunos foi fundamental para as trocas e aprendizados de todos.

Definimos que algumas aulas teriam a realização de dinâmicas, outras a participação de convidados e as demais a participação dos alunos com análises de produtos culturais, midiáticos e/ou jornalísticos. No que se refere às dinâmicas, estas já se iniciaram na apresentação da disciplina, na primeira aula, com a realização da dinâmica Caminhada dos Privilégios, como relatamos na introdução deste artigo. Outra dinâmica utilizada para compreender as atribuições de gênero que marcam os corpos ocorreu a partir da leitura do texto "O Corpo", de Novas Cartas Portuguesas (Maria Isabel BARRENO et al., 1974), e ainda uma atividade com sinônimos, pensando na abundante proliferação de discursos que é responsável pela criação da identidade na relação com o Outro, especialmente aqueles fora da norma (SILVA, 2000; Michel FOUCAULT, 2014).

Os alunos tiveram como responsabilidade apresentar produtos culturais, midiáticos e jornalísticos que se relacionassem com as temáticas discutidas em sala de aula. A atividade realizada em grupos teve como proposta o diálogo entre teoria e prática e a reflexão sobre a agência dos jornalistas e comunicadores na construção das narrativas. As escolhas referentes aos produtos foram muito variadas, incluindo trechos de filmes, vídeos do YouTube e reportagens da mídia hegemônica e da independente. Entre elas, tivemos exemplos que foram considerados pelos estudantes como positivos, que promoviam rupturas com as normas sociais debatidas anteriormente, e negativos, que reforçavam as hierarquias de gênero. Acreditamos que a proposta foi importante ainda para a reflexão sobre o que seria produzido no trabalho final da disciplina.

Para o trabalho final da disciplina, que poderia ser realizado tanto em grupos, duplas ou individualmente, foi proposto para a turma que desenvolvesse um produto jornalístico que tivesse como objetivo transgredir em relação às práticas jornalísticas hegemônicas no que se refere às questões de gênero. Os trabalhos finais foram bem variados, tais como: - dois programas de rádio, sendo um deles em formato de entrevista sobre arte e visibilidade das temáticas que envolvem sujeitos lésbicas, gays, bissexuais, transexuais e travestis (LGBTs) e outro sobre um histórico das lutas feministas no Brasil; - um programa televisivo com entrevistas sobre visibilidade LGBT; - uma reportagem multimídia com o tema "Identidades", com um conjunto de reportagens que abordam como as pessoas se percebem e como os padrões impostos socialmente influenciam as manifestações dessas identidades; - um fanzine sobre a imprensa feminina e feminista, destacando as primeiras publicações no mundo e no Brasil, e, no final, as atuais publicações brasileiras; - três reportagens em texto, sendo uma sobre a vida de um jovem transgênero, a outra sobre a vida de um jovem homossexual, e a terceira reportagem sobre as mulheres que sofrem assédio nas redações jornalísticas; - um texto mais teórico relacionando as concepções de gênero com os valoresnotícia nas reportagens esportivas; - uma crônica sobre a mudança de pensamento do autor sobre as perspectivas de gênero e a sua experiência ao entrevistar uma travesti.

\section{Considerações finais}

A experiência docente compartilhada na disciplina Jornalismo e Gênero foi única, desafiadora, construtiva e transformadora das práticas e relações entre nós, que estávamos diretamente envolvidas(Os) com a disciplina, assim como de outras(os) professoras(es) e estudantes do curso de Jornalismo da UFSC.

Durante o cotidiano de desenvolvimento da disciplina, muitas(os) colegas professoras(es) relataram as mudanças nos interesses temáticos dos estudantes ao realizarem suas reportagens e demais trabalhos em aula, assim como ao escolherem seus temas para o Trabalho Final de Conclusão de Curso (TCC), os quais passaram a priorizar o trabalho com a temática de Gênero no Jornalismo sobre diversas perspectivas. Por parte das(os) estudantes, os relatos foram no sentido de 
terem tido a oportunidade de pensar sobre as práticas sociais e jornalísticas sob outros olhares, tendo discernimento e embasamento teórico sobre a diversidade e complexidade em torno das questões de identidades de gênero e do quanto essas questões estão presentes em todas as temáticas possíveis de serem abordadas pelo Jornalismo.

As transformações ocorridas no curso de Jornalismo da UFSC - iniciadas a partir do protagonismo das estudantes do Coletivo Jornalismo Sem Machismo - alteraram em definitivo a formação de jovens estudantes em Jornalismo e também o modo de aprendizado em sala de aula no que se refere ao relacionamento professores e alunos. Foi desafiador buscar conhecimentos, leituras sobre a temática conjuntamente com os estudantes e aprender de modo coletivo, horizontalmente, respeitando as diferenças uns dos outros.

A emergência da disciplina pode ser constatada também na grande procura dos estudantes por cursá-la, tanto que, apesar de não ter tido uma edição em 2017/2, por organização da oferta de outras disciplinas pelo Departamento, no primeiro semestre de 2018 a disciplina voltou a ser ofertada e já houve outra edição da disciplina no segundo semestre de 2018. Consideramos, neste sentido, que a disciplina Jornalismo e Gênero ruma para uma consolidação, bem como os estudos de gênero no campo da Comunicação, sendo imprescindível para a construção de novos conhecimentos entre os futuros jornalistas.

Cabe destacar, por fim, a urgência que sentimos de que as temáticas debatidas na disciplina específica não se restrinjam ao ambiente e espaço das aulas de Jornalismo e Gênero. Tratar sobre gênero e sexualidade, assim como outros marcadores de diferença, como raça, classe, etnia e geração, enquanto assuntos transversais, se torna outro grande desafio da empreitada assumida por nós e por um expressivo número de estudantes que aposta no Jornalismo como prática de transformação social.

\section{Referências}

ALMEIDA, Gabriela Cavalcanti Carneiro de. A mulher na pesquisa em jornalismo: teses e dissertações defendidas em Programas de Pós-Graduação em Jornalismo e Comunicação do Brasil (1972-2015). 2018. 149f. Dissertação (Mestrado em Jornalismo) - Universidade Estadual de Ponta Grossa, Ponta Grossa, RS, Brasil, 2018.

BARRENO, Maria Isabel et al. Novas Cartas Portuguesas. São Paulo: Círculo do Livro, 1974.

BENTO, Berenice Alves de Melo. O que é transexualidade. São Paulo: Brasiliense, 2008.

BUTLER, Judith. Problemas de gênero: feminismo e subversão da identidade. Rio de Janeiro: Civilização Brasileira, 2013.

COLETIVO JORNALISMO SEM MACHISMO. Página oficial no Facebook. Disponível em https:// www.facebook.com/jorsemmachismo/. Acesso em 10/08/2018.

CRENSHAW, Kimberlé W. "A interseccionalidade na discriminação de raça e gênero". In: W.AA. Cruzamento: raça e gênero. Brasília: EDUnifem, 2004, p. 7-16.

DAVIS, Angela. Mulheres, raça e classe. Rio de Janeiro: Boitempo, 2016.

ESCOSTEGUY, Ana Carolina; MESSA, Márcia. "Os estudos de gênero na pesquisa em comunicação". Revista Contemporânea, Salvador, v. 4, p. 65-82, 2006.

FISCHER, Rosa Maria Bueno. "O dispositivo pedagógico da mídia: modos de educar na (e pela) TV". Revista Educação e Pesquisa, São Paulo, v. 28, n. 1, p. 151-162, jan./jun. 2002.

FOUCAULT, Michel. História da sexualidade - A vontade de saber. São Paulo: Paz e Terra, 2014.

FRIEDAN, Betty. “O problema sem nome”. In: FRIEDAN, Betty. Mística feminina. Petrópolis: Vozes, 1971. p. 17-31.

FRY, Peter; MacRAE, Edward John Baptista das Neves. O que é homossexualidade. 7. ed. São Paulo: Brasiliense, 1991.

GUSTAFSON, Jessica. Jornalistas e Feministas - A construção da perspectiva de gênero no Jornalismo. Florianópolis: Insular, 2019.

HALL, Stuart. A identidade cultural na pós-modernidade. 10. ed. Rio de Janeiro: DP\&A, 2005.

HARAWAY, Donna. "Saberes localizados: A questão da ciência para o feminismo e o privilégio da perspectiva parcial”. Cadernos Pagu, Campinas, Unicamp, n. 5, p. 7-41, 1995. 
HARAWAY, Donna. "'Gênero' para um dicionário marxista: a política sexual de uma palavra”. Cadernos Pagu, Campinas, Unicamp, n. 22, p. 201-246, 2004.

LAURETIS, Teresa de. "A tecnologia de gênero". In: HOLANDA, Heloisa Buarque de (Org.). Tendências e impasses: o feminismo como crítica cultural. Rio de Janeiro: Rocco, 1994. p. 206-242.

LOURO, Guacira Lopes. Um corpo estranho: ensaios sobre sexualidade e teoria queer. 1. ed. Belo Horizonte: Autêntica, 2008.

LUGONES, María. "Rumo a um feminismo descolonial". Revista Estudos Feministas, Florianópolis, v. 22, n. 3, p. 935-952, 2014.

MARTINEZ, Monica; LAGO, Cláudia; LAGO, Mara Coelho de Souza. "Estudos de gênero na pesquisa em Jornalismo no Brasil: uma tênue relação". Revista Famecos - Midia, Cultura e Tecnologia, Porto Alegre, PUC, v. 23, n. 2, 2016. ID22464

MOITA LOPES, Luiz Paulo da. "Falta homem até pra homem: a construção da masculinidade hegemônica no discurso midiático". In: HEBERLE, Viviane Maria; OSTERMANN, Ana Cristina; FIGUEIREDO, Débora de Carvalho (Orgs.). Linguagem e gênero: no trabalho, na mídia e em outros contextos. Florianópolis: EDUFSC, 2006. p. 131-157.

NASCIMENTO, Fernanda. Bicha (nem tão) má - LGBTs em telenovelas. Rio de Janeiro: Multifoco, 2015.

PEDRO, Joana Maria. "Traduzindo o debate: o uso da categoria gênero na pesquisa histórica". História, São Paulo, USP, v. 24, n. 1, p. 77-98, 2005.

PEREIRA, Eduarda; BONALDO, Manoela dos Santos. "Coletivo Jornalismo sem Machismo: Militância e produção de conhecimento no curso de jornalismo da UFSC". I AQUENDA DE COMUNICAÇÃO, GÊNEROS E SEXUALIDADES. Anais... Ed. I, Porto Alegre, RS, 2018. Disponível em https://aquenda.files.wordpress.com/ 2019/04/eduarda-pereira-e-manoela-dos-santos-bonaldo.pdf. Acesso em 10/08/2018.

RUBIN, Gayle. "Pensando sobre sexo: notas para uma teoria radical da política da sexualidade". In: RUBIN, Gayle. Políticas do Sexo. São Paulo: Ubu, 2017. p. 63-128.

SARTI, Cynthia Andersen. "O feminismo brasileiro desde os anos 1970: revisitando uma trajetória". Revista Estudos Feministas, Florianópolis, v. 12, n. 2, p. 35-50, 2004.

SCOTT, Joan W. "Gênero: uma categoria útil de análise histórica". Educação e Realidade, Porto Alegre, UFRGS, v. 20, n. 2, p. 71-79, 1995.

SEFFNER, Fernando. Derives da masculinidade: representação, identidade e diferença no âmbito da masculinidade bissexual. 2004. 260f. Tese (Doutorado) - Programa de Pós-Graduação em Educação, Porto Alegre, Universidade Federal do Rio Grande do Sul, 2004.

SILVA, Tomaz Tadeu da. "A produção social da identidade e da diferença". In: SILVA, Tomaz Tadeu da (Org.). Identidade e diferença. Petrópolis: Vozes, 2000. p. 73-102.

STOCKER, Pâmela; DALMASO, Silvana. "Uma questão de gênero: ofensas de leitores à Dilma Rousseff no Facebook da Folha". Revista Estudos Feministas, v. 24, n. 3, p. 679-690, setembro/dezembro 2016.

TOMAZETTI, Tainan Pauli; CORUJA, Paula. "Relações de gênero: os desafios para além das binariedades, identidades e representações". In: JACKS, Nilda et al. Meios e Audiências III: reconfigurações dos estudos de recepção. Porto Alegre: Sulina, 2017. p. 171-192.

VEIGA DA SILVA, Marcia. Masculino, o gênero do Jornalismo: Modos de produção das notícias. Florianópolis: Insular, 2014.

VEIGA DA SILVA, Marcia. Saberes para a profissão, sujeitos possíveis: um olhar sobre a formação universitária dos jornalistas e a implicação dos regimes de saber-poder nas possibilidades de encontro com a alteridade. 2015. 276f. Tese (Doutorado) - Programa de Pós-Graduação em Comunicação e Informação, Universidade Federal do Rio Grande do Sul, Porto Alegre, RS, Brasil, 2015. 
Daiane Bertasso (daianebertasso@gmail.com) é Professora Adjunta no Departamento de Jornalismo da Universidade Federal de Santa Catarina (UFSC) e no Programa de Pós-Graduação em Jornalismo da UFSC. Pesquisadora nos Grupos de Pesquisa do CNPq Jornalismo, Cultura e Sociedade (UFSC) e TRANSVERSO: Estudos em Jornalismo, Interesse Público e Crítica (UFSC).

Jessica Gustafson (je.g.costa@gmail.com) é doutoranda no Programa de Pós-Graduação em Jornalismo (PPGJOR) da Universidade Federal de Santa Catarina, mestra em Jornalismo (PPGJOR/ UFSC), especialista em Gênero e Sexualidade pelo Centro Latino-Americano em Sexualidade e Direitos Humanos (CLAM/IMS/UERJ). Integra o grupo de pesquisa TRANSVERSO: Estudos em Jornalismo, Interesse Público e Crítica (UFSC).

Fernanda Nascimento (fn.imprensa@gmail.com) é Professora Substituta no Departamento de Jornalismo da Universidade Federal de Santa Catarina (UFSC). Doutoranda no Programa de Pós-Graduação Interdisciplinar em Ciências Humanas (PPGICH) na mesma instituição. Bolsista Capes.

\section{COMO CITAR ESSE ARTIGO DE ACORDO COM AS NORMAS DA REVISTA}

BERTASSO, Daiane; NASCIMENTO, Fernanda; GUSTAFSON, Jessica. "Jornalismo e gênero: a emergência de uma disciplina e um relato de docência compartilhada". Revista Estudos Feministas, Florianópolis, v. 28, n. 2, e58720, 2020.

\section{CONTRIBUIÇÃO DE AUTORIA}

Daiane Bertasso: concepção da proposta, coleta de dados e análise de dados, elaboração do manuscrito, redação, discussão de resultados.

Fernanda Nascimento: concepção da proposta, coleta de dados e análise de dados, elaboração do manuscrito, redação, discussão de resultados.

Jessica Gustafson: concepção da proposta, coleta de dados e análise de dados, elaboração do manuscrito, redação, discussão de resultados.

\section{FINANCIAMENTO}

O presente trabalho foi realizado com apoio da Coordenação de Aperfeiçoamento de Pessoal de Nível Superior - Brasil (CAPES) - Código de Financiamento 001.

\section{CONSENTIMENTO DE USO DE IMAGEM}

Não se aplica.

APROVAÇÃO DE COMITÊ DE ÉTICA EM PESQUISA

Não se aplica.

CONFLITO DE INTERESSES

Não se aplica.

LICENÇA DE USO

Este artigo está licenciado sob a Licença Creative Commons CC-BY International. Com essa licença você pode compartilhar, adaptar, criar para qualquer fim, desde que atribua a autoria da obra.

\section{HISTÓRICO}

Recebido em 18/08/2018

Reapresentado em 24/10/2019

Aprovado em 01/11/2019 